\title{
Adding the Extra 5 Percent: Undergraduate TA's Creating Value in the Class- room
}

\section{Mrs. Alicia Baumann, Arizona State University}

Ali Baumann received her master's degree in Electrical Engineering from the University of Wyoming before working as senior systems engineer at General Dynamics C4 Systems. She is now part of the freshman engineering education team in the Ira A. Fulton Schools of Engineering at Arizona State University. Currently, she focuses on enhancing the curriculum for the freshman engineering program to incorporate industry standards into hands-on design projects. She is an instructor for the Introduction to Engineering program, Engineering Transfer Success program, Engineering UGTA program, and the Electrical Engineering department at ASU. She is a 3-time winner of the "Fulton Top 5\% Teaching Award" and 2-time winner of "Badass Women of ASU". Her philosophy boasts incorporating large scale systems engineering techniques into collegiate engineering curriculum to better prepare upcoming professionals and develop a student's resume from day one.

\section{Dr. Stephanie M. Gillespie, Arizona State University}

Stephanie Gillespie joined the ASU@EPICS program after finishing her Ph.D. in Electrical and Computer Engineering from the Georgia Institute of Technology. She has extensive experience in K-12 outreach and curriculum development, and is passionate about giving students opportunities to make a difference throughout their academic career. As the EPICS Director of Instruction, Stephanie leads the EPICS program's curriculum development, EPICS-Community College program, and program assessment efforts. She received her M.S.E.C.E. from Georgia Tech in 2013, and her B.S.E.E. from the University of Miami in 2012 .

\section{Ms. Nicolle Sanchez, Arizona State University}




\section{Adding the extra 5\%: UGTAs Creating Value in the Classroom}

\section{Introduction}

The undergraduate teaching assistant (UGTA) program at the Ira A. Fulton Schools of Engineering at Arizona State University has evolved since 2009 and this paper will discuss a new approach to using UGTAs throughout a large scale, multi-disciplinary, multiple campus engineering program. This approach was created from the foundation of the Kern Entrepreneurship Education Network (KEEN) entrepreneurial mindset focusing on the 3 C's; curiosity, connections, and creating value [1]. While many programs utilize UGTAs in engineering or other curriculums, few have done so at an entire college scale spanning both oncampus and online courses or focused on the growth and mentorship of the UGTAs themselves. The goal of the Fulton UGTA program is to provide UGTAs with the motivation to create new value in the classroom that wouldn't otherwise be available and promote the professional development of the UGTA by providing an inside look into active learning and pedagogy development. This paper will introduce the evolution and logistics of the newly revised Fulton UGTA program. This paper explores the applicability of UGTAs across a wide range of courses, examines any differences seen between new versus returning UGTA experiences, and analyze if the updated program provided UGTA students with increased empowerment and motivation to continually engage with co-curricular engineering programs.

\section{Literature Review}

As the environment of the traditional classroom continues to evolve to a more active and engaging experience, professors are continually searching for new ways to interact with their undergraduate engineering students. The utilization of teaching assistants in the classroom is one approach that instructors use to help with implementation of active learning activities and an option to provide peer-to-peer guidance. While teaching assistants can come in both flavors of graduate and undergraduate, multiple studies show the positive effects of using undergraduate teaching assistants (UGTA) on the overall student experience.

In a 2015 study by Arizona State University Schools of Engineering [2], undergraduate student retention practices were analyzed to determine the factors of retention of first-year engineering programs. Comparisons in the value of curricular and co-curricular experiences as well as student support programs showed that providing peer mentors as role models or UGTAs helped students better identify and connect with their program [2].

UGTAs have been found to not only increase the outlook of a student's perception on their experience, but to overall improve the comprehension of course material. Crowe analyzed the performance of undergraduate sociology students by comparing the mastery of course objectives for students who in a section taught with the assistance of UGTAs and students who only had the instructor to present the material [3]. The final results proved that students with access to UGTAs earned higher grades and performed better on at least half of the learning outcomes. While the results lead to a belief that the UGTAs provide additional content, conversations with the UGTAs exposed that students used UGTAs as an intermediary contact to help students falling behind and provide clarifications outside of class [3]. 
Along with definitive evidence showing that the use of UGTAs improves the performance of undergraduate students, a study by McVey at University of Kansas Engineering [4] analyzed feedback from undergraduates regarding the perception of the "undergraduate teaching fellows." Results show that $88 \%$ of respondents believed their learning was better with the presence of a TA and 79\% indicated the mentors positively impacted their student experience [4]. It is evident that the use of UGTAs in engineering courses have various positive impacts from increased engineering identity, overall course comprehension, and perception of learning experience [2-4].

While the need for UGTAs is clear and the benefits expand both academic and social effects, the appropriate training and model for using a UGTA is widely disconnected and currently dependent on size and type of classroom. There is a common thread in most TA training to focus on three main areas. Wheeler et al. describe these as theory (how students learn), pedagogy (helping students learn better), and practical (course/department expectations including roles, grading and safety) [5]. Multiple universities provide in-person trainings of various lengths, ranging from a couple days to a few weeks or require UGTAs to enroll in a specific course to provide addition material and group meetings [5] [6]. The University of Kansas prepares UGTAs through participation of in-person meetings over the course of the semester focusing on diversity and inclusion, student motivation and engagement, and mentoring strategies [4]. Phillips et al [7] created one of the most comprehensive TA training modes for their first-year engineering UGTAs consisting of five parts; orientation, informal peer mentoring, grading training, lab training, and content training. In this program, heavy emphasis is made on content training by attending weekly lab training, as well as assignment training. This preparation enforces the mastery of the content delivery, but is focused on only one course in the first-year engineering curriculum so is not scalable to offering UGTAs in multiple course programs. Portions of all of these models have been incorporated into the new ASU Fulton UGTA program to allow for accountability and mentoring of the UGTAs, while focusing on generalized training instruction so it is applicable to all forms of ASU Fulton UGTAs; these include on-campus/online, lab/lecture, and technical/developmental.

The types of roles a UGTA may take in a classroom are extremely varied, including attending class, leading parts of class, helping to create or grade homework, assisting with labs, maintaining labs, hosting exam reviews, hosting office hours, hosting specific help session, and even helping to setup end of course evaluation surveys [8]. Other programs utilize UGTAs as pure assistants to clerical tasks (for attendance, recording grades) while occasionally leading group discussions or review sessions [9] [10]. However, the type of activities a UGTA can successfully assist with is often most closely dictated by the type of class structure. This is especially problematic when integrating UGTAs into online courses, since many of the options suggested by Gehringer are only available during an in-person environment.

Furthermore, even with various degrees of usage for UGTAs, a commonality appears in many programs indicating that UGTAs are not feeling they are gaining professional development skills that will advance their careers. Results from the program created by Phillips show that the majority of UGTAs all had higher competency of the course material due to the intense amount of lab and assignment training, but the overall impact made to the students in their assigned class was low, attributed to having no creativity within the rigid training structure [7]. A study by 
Shannon [11] revealed that TAs who attend departmental training were more likely to have positive ratings in the classroom, but the best UGTA training was viewed as prior experience with teaching. Small amounts of training (1 day or less) that often focus on university and department policies do not provide enough time for UGTAs to learn and more importantly develop a comprehension of pedagogical skills, limiting the professional development achieved.

From a small sample size of 6 graduate TAs at Texas Tech University, survey results suggested that graduate teaching assistants view preparedness, fair grading, and enthusiasm as the most important aspects of being an effective TA, while topics such as "treats all students with respect", "encourages students to ask questions", "cares about student success", and "is an expert in the content area" were the lowest traits on the ranked list [12], indicating that TAs are not being pushed to view their UGTA role as a trial for a potential career in academia where the goal is to focus on the students. Results from a study performed by Weidert et al. show many selfreflected benefits of an undergraduate teaching assistant experience, including confidence, team abilities, and personal insight [13]. Items such as "more likely to become a professor" and "prepared me for a career after graduation" had the lowest results, indicating that the realistic preview of a career in academia actually pushed students away and/or the students were not developing skills required to confidently approach academia as a potential career.

Recognizing that many current UGTA programs are falling short of empowering their UGTAs to recognize the impact being made in the classroom, the new UGTA program at the Ira A. Fulton Schools of Engineering at Arizona State University is determined to make the experience motivational for the UGTA. One of the common pitfalls seen throughout these studies is the lack of opportunity for the UGTA to be creative in their role in the classroom. UGTAs are most likely to instruct and try to help students in a manner in which they were instructed and assisted. This repetitive cycles stunts innovation in the classroom unless the TAs are provided opportunities to learn and practice new techniques of pedagogy. Shannon highlights that as curriculum expands, so does the need for the type of training efforts for teaching assistants [11]. A one size fits all approach to TA preparation cannot be expected to maximize student learning outcomes across all types of environments including labs, recitations, online courses, and more.

Changing the mindset from assuming UGTAs require guided tasks of responsibilities means thinking of them as an employee of an organizational culture. Leadership in any organization generally wishes to encourage employee satisfaction and empowerment, so the ASU Fulton UGTA program uses a cognitive model of empowerment along with the KEEN entrepreneurial mindset approach as the basis for the program. Thomas and Velthouse created a cognitive model of empowerment to increase worker motivation and satisfaction by identifying four task assessments: sense of impact, competence, meaningfulness, and choice [14]. By recognizing that a classic paradigm of strict control over rewards and punishments leads to workers determined to comply, a new paradigm was developed introducing relaxed control and commitment to the task. The main purpose of this cognitive model is to show that by fostering an intrinsic task motivation among your workers, the individual will gain more empowerment through the four different assessment areas. As workers are provided with choices in their task goals that they find value in according to their own beliefs, they will feel more qualified to achieve the goal and feel they have an impact to make a difference. Focusing on leading UGTAs through the use of this model is expected to increase the empowerment as seen by the UGTA. Similarly, Weidert et al. found 
evidence suggesting that increased UGTA responsibilities is associated with more overall satisfaction, enjoyment, and perceived benefits of the position [13]. Last, the KEEN foundation stresses that today's engineers must become more entrepreneurially minded to stay competitive in the current economic climate [1]. An entrepreneurial mindset consists of an engineer who is curious, fosters connections, and creates value [1]. While many UGTA programs claim to satisfy these three values, many of the above findings showcased that UGTAs were not feeling the impact of their assistance, nor were they given the choice to try new approaches in teaching.

These findings and models lead to the foundation of the ASU Fulton UGTA program where the UGTAs are in charge of their own intrinsic tasks and responsibilities. Given that the ASU Fulton UGTA program is a complex program utilizing UGTAs in classes of every year and discipline on a variety of campuses and platforms, it is crucial to implement a variety of support systems to enhance the UGTA experience. Owen [15] reported that three facets of a successful UGTA program would include learning about teaching/learning, observation and feedback, and peer-group support. Many examples given in these findings were incorporated into the ASU Fulton UGTA program such as conveying pedagogy through directed readings and websites, using observations of a UGTA performance to increase the effectiveness, and implementing discussion boards for UGTAs to share concerns or experiences.

\section{Background}

When Arizona State University first started its undergraduate teaching assistant (UGTA) program in the fall 2009 semester, the goal was to facilitate active learning specifically for the engineering classes [16]. Evaluation of this program resulted in feedback from 1600 engineering students with an overwhelming majority indicating that the UGTA helped students understand course material, provided resources to succeed, and provided help outside of class. Areas identified for improvement were better integration of the UGTA in the course and providing the UGTAs with training on public speaking and activity development.

The program evolved into a structured School-level initiative rather than departmental efforts. UGTAs submitted a formal application, were assigned to work with a specific faculty member for 5 hours per week, and enrolled in a one-credit course facilitated online to provide trainings and assignments to complete as a UGTA which was assessed as a pass/fail grade. This effort of a single course created a communication channel between the UGTAs and the ASU Fulton Office of Academic and Student Affairs, helping with accountability and logistical needs of managing the program.

Assignments in the 1-credit course UGTA preparation course included two reading assignments with follow-up online discussion forum posts relating the article content to their role as a UGTA and an implementation plan to introduce the reading outcomes for their specific class. Other assignments included a focus on academic integrity, creation of a resume, and a reflection summary. Student feedback of the UGTAs who participated in this formal program revealed that a majority of students felt that their UGTA was prepared for in-class activities, helped to understand course material, provided help outside of the classroom, helped them succeed, and encouraged collaboration. However, feedback also suggested that there was improvement for integrating the role of the UGTA within the course. 
As the program evolved, generic assignment suggestions were added to the UGTA set of responsibilities to allow for UGTAs to lead review sessions, office hours, discussion board management, or "muddiest point" surveys. These options provided variety for the UGTAs to spread out their 5 hours per week employment, since most courses did not provide 5 hours per week of active learning activities, while also better incorporating UGTAs into different course types from lab settings to lectures to online courses.

In 2016, the program expanded to providing returning UGTAs (UGTAs who had worked for the program in a prior semester) with an advanced version of the 1-credit course requiring students to become more cognizant of teaching pedagogy and the applications in their assigned course. The required assignments had students watching video presentations on topics such as "understanding student motivation", "inclusiveness training", and "technology strategies" which they were then tested on for comprehension. Additional work was added for returning UGTAs to post required reflections on discussion boards and preparing their own video presentations on the best practices they learned while working as a UGTA. The first-time UGTA program was also updated to include a required assignment for UGTAs to create a video presentation on the entrepreneurial mindset. All video presentations that were made were then required to be critiqued by other UGTAs as part of the course. The updates made in 2016 were clearly in an effort to better explain to UGTAs the pedagogical practices used in developing curriculum, but did not offer any application of that new knowledge into the classroom. General consensus from the faculty had indicated that UGTAs were unsure of ways to help in the classroom and relied solely on the direction of faculty before engaging with students. Many participating faculty had also fallen into a routine of using UGTAs for menial tasks like grading, making copies, and holding poorly attended office hours, all tasks contradictory to the original goals of the ASU Fulton UGTA program which encouraged developing UGTAs to assist with active learning in the classroom. Results from the 2009 study provide traction to continue the program with results from both the 2009 and 2016 program justifying a need for improved training in active learning applications.

\section{Methods}

The newest version of the ASU Fulton UGTA program incorporates facets from many of the above mentioned types of programs. First off, two different flavors of assistants were included for this program, a traditional UGTA and a section leader (SL). Both versions have the same responsibilities but SLs are assigned to the "ASU Experience" first-semester course. These types of assistants are chosen based on leadership experience and a dedication to service, as they will be engaging directly with a small group of first-year students and are expected to act as role models and mentors to their assigned groups. This type of course is an introduction to success practices for new college students, and therefore requires a well-informed upperclass student to provide experience and guidance to the students.

An initial 2-hour orientation is provided to acclimate new UGTAs to the high-level purpose of the program and introduce the UGTA program teaching staff consisting of one instructor and one staff liaison. After the initial orientation, specific course training is provided by the assigned instructor for the assisted course. Based on the suggestions by Owen [15], each UGTA is 
required to enroll in a 1-credit hour course that provides web-based training and materials to help UGTAs prepare activities and learn pedagogical practices. Embedded in that course is a common discussion board managed by the instructing staff where students are able to post questions and conversations on logistics, ideas, and tips also satisfying the "peer-led group" support system encouraged by Owen [15]. To mitigate the potential misuse or underutilization of UGTAs and based on Weidert's findings of increased responsibilities leading to higher satisfaction in UGTAs [13], the UGTAs are assigned 12 assignments to complete throughout each semester they are hired, and are expected to assist for 5 hours per week. The UGTA program employs between 300 and 400 UGTAs every semester, spanning courses throughout all six schools of engineering, assisting in a variety of class structures from technical lectures to labs to open-ended design to online courses.

The required assistance of 5 hours per week maximum is documented in an agreement between the UGTA and the mentoring faculty of the assigned course. A suggested list of potential weekly uses is provided in the agreement to guide faculty towards proper use of the UGTA and encourage the fostering of student and faculty connections as much as possible, which is a key value of the KEEN entrepreneurial mindset. Selections are made at the beginning of the semester and associated with an expected number of hours per week to perform the tasks. UGTAs are trained during orientation that there is no grading allowed or creation of assessments to be used in the classroom, as well as instructed to host no more than 2 office hours per week to encourage active learning interactions over private tutoring. Table 1 below lists the options of UGTA weekly expectations that faculty can assign to their UGTAs.

Table 1: Options for Weekly Responsibilities of Fulton UGTAs

\begin{tabular}{|l|l|}
\hline Attend Lecture & Find/Repair Broken Equipment \\
Attend Lab & Proctor Exams \\
Attend Recitation & Discussion Board Management \\
Course Preparation & Faculty Mentoring Meetings \\
Manage lab supplies & \\
\hline
\end{tabular}

Using the cognitive model of empowerment developed by Thomas stating that intrinsic task motivation leads to employee empowerment [14] and combining that theory with the $3 \mathrm{C}$ 's of the KEEN entrepreneurial mindset, the 12 assignments were developed to promote UGTA choice, training, connecting with students, and the meaningfulness of experiences that impact students. The 12 assignments are listed below in Table 2, categorized as either "Required" or "SelfChosen". 
Table 2: Full list of Fulton UGTA assignments

\begin{tabular}{|l|l|}
\hline Assignment & Type \\
\hline UGTA-Faculty Contract & Required \\
FERPA Training \& Quiz & \\
Title IX Training \& Quiz & \\
Students in Distress Training \& Quiz & \\
Entrepreneurial Mindset Research & \\
UGTA Resume Blurb & \\
UGTA End-of-Course Survey & \\
UGTA-Faculty Year-End Evaluation & \\
\hline Optional Assignment Choice \#1-4 & Self-Chosen \\
\hline
\end{tabular}

While all 12 are required to be completed, only 8 are common for all UGTAs and SLs that are generic enough to apply to every UGTA. These 8 assignments begin with an agreement of responsibilities between the UGTA and the assigned course instructor where the terms of the weekly expectations and the "self-chosen" assignments are decided. From there, three training assignments are provided in accordance with the university's employment requirements. An assignment analyzing the use of the entrepreneurial mindset is required to research current innovations in teaching. And finally, the last three assignments are completed at the end of the UGTA semester to reflect on achievements through the UGTA position for their resume, complete a final survey of experience, and complete a mandatory faculty evaluation to learn about their strengths, weaknesses, and performance as a UGTA from their mentoring instructor.

The remaining 4 of the 12 assignments are chosen from a list of potential activities designed to encourage active learning, self-reflection, or new innovations in curriculum. This is the chance for the UGTA to add value to the class in ways not typically done by an instructor. Each "selfchosen" assignment is supplied with a full introduction to the importance and best uses of the task, required material for submission of the assignment, and supplemental sources to use in preparation of the material. UGTAs chose from a list of 23 different options of "self-chosen" assignments which is designed to provide options for all types of UGTAs and SLs covering a variety of course structures. The full list can be found in Table 3.

Table 3: Self-chosen assignment options

\begin{tabular}{|c|c|c|}
\hline $\begin{array}{ll}\text { - } & \text { Muddiest Point Survey } \\
& \text { \& Lesson } \\
\text { - } & \text { Innovation Workshop } \\
\text { - } & \text { Active Learning In-Class } \\
& \text { Lesson } \\
\text { - } & \text { Practice Run Hint List } \\
\text { - } & \text { Exam Review Session } \\
\text { - } & \text { Lead a Lecture } \\
\text { - } & \text { Hashtag War }\end{array}$ & $\begin{array}{ll}\text { - } & \text { Mentor Student through } \\
\text { Engagement Opportunity } \\
\text { - } \\
\text { Career Services } \\
\text { Preparation } \\
\text { - } \\
\text { Discussion Board - } 3 \\
\text { Sample Homework } \\
\text { Questions } \\
\text { - } \\
\text { Discussion Board - } \\
\text { TEDTalk }\end{array}$ & $\begin{array}{l}\text { - Troubleshooting } \\
\text { Strategies and Experience } \\
\text { - Recognizing your } \\
\text { Implicit Bias } \\
\text { - Feedback on a UGTA } \\
\text { Performance } \\
\text { - AIP/Ethics Training and } \\
\text { Lesson } \\
\text { - } 4-Y e a r \text { Plan Draft }\end{array}$ \\
\hline
\end{tabular}




\begin{tabular}{|c|c|c|}
\hline $\begin{array}{l}\text { - Guest Speaker Interview } \\
\text { - Peer Review Lab Report } \\
\text { - Conflict Resolution } \\
\text { Practices }\end{array}$ & $\begin{array}{l}\text { Discussion Board - } \\
\text { Relevant Journal Article } \\
\text { Discussion Board - } \\
\text { Relevant Engineering } \\
\text { Technology }\end{array}$ & $\begin{array}{l}\text { - Prototype Part for Class } \\
\text { Lesson/Purpose } \\
\text { - Instructor Chosen } \\
\text { Assignment }\end{array}$ \\
\hline
\end{tabular}

Common to Gehringer's [8] list of faculty preferred UGTA tasks, options such as active learning lessons, exam review sessions, leading a class, and providing clarifications to confusing topics are included as staples for UGTAs to select to complete during the semester. However, realizing that a portion of our classes are fully online, non-traditional options were provided including discussion board prompts, practicing homework assignments, or peer reviewing student's work to ensure that online UGTAs can still interact and provide value through a digital platform. Additional options were presented as choices to encourage new practices such as social media challenges or guest speaker interviews. Owen suggested that one necessary practice for a successful UGTA was observation and feedback [15], and while the UGTA will get overall performance feedback at the end of the semester from the assigned faculty, additional options were provided to those seeking a more in depth reflection by offering an online survey assessment deciphering a UGTA's implicit bias so they can understand their inherent approach towards diversity in students, as well as an option to have a detailed review of a UGTA performance in front of a class critiquing the teaching style presented by the UGTA. All additional options in the above table not discussed here were provided in an attempt to offer mentoring and leadership activities for those courses deemed "success courses".

New with this model is the removal of a specific advanced curriculum for experienced UGTAs. All UGTAs are given the same expectations because the course now offers the ability to choose the level and type of engagement through the self-chosen assignments detailed in the 1-credit hour course. By offering choices, the UGTA has the ability to change the workload every semester while still engaging in the classroom. Returning UGTAs can choose more complex types of activities such as workshops, one-on-one student mentoring, or interviewing guest speakers to challenge themselves.

The goal of offering choices in the tasks available to the UGTAs was not only to be able to provide a model that is scalable across a variety of course types and structures, but to hopefully empower students to find motivation in being a UGTA as seen in Thomas' cognitive empowerment model [14] and allow UGTAs to be curious about different teaching methods based on the KEEN entrepreneurial mindset, so as to not just use the experience as a resume builder. Work done by Frymier et al [17] provides an instrument to measure learner empowerment based on the cognitive empowerment model of Thomas [14] which will be used in this case to measure UGTA perceptions of empowerment in both the 1-credit UGTA course as well as the course the UGTA is assigned to for assistance. The instrument consisted of 30 statements categorized to measure empowerment across the four assessment areas of the cognitive model: meaningfulness, competence, impact, and choice. These 30 statements were divided into two categories to better match the approach of the fully online UGTA 1-credit hour course versus the assigned course the UGTA assisted with, as some of the statements of learner empowerment were very specific to a student learner environment as opposed to the student assisting environment we are evaluating. Students were asked to respond with a number from 0 
(strongly disagree with the statement) to 4 (strongly agree with the statement). The following statements were used to determine UGTA empowerment based on the Frymeir instrument [17] as seen in Tables 4 and 5. Each statement is categorized to a task assessment area following the instrument created by Frymier.

Table 4: 1-Credit Hour (FSE 201) UGTA Course Empowerment Survey

\begin{tabular}{|c|c|}
\hline 1. & Class (FSE 201) is consistent with my values. (ME) \\
\hline 2. & I actively participate in all the tasks required of my class (FSE 201). (IM) \\
\hline 3. & I typically do more work than is required by the syllabus. $(\mathrm{CH})$ \\
\hline 4. & I am overwhelmed by all the work my class (FSE 201) requires. (CO) \\
\hline 5. & I work hard for class (FSE 201) because I want to, not because I have to. (ME) \\
\hline 6. & I have a choice in the methods I can use to perform my work. $(\mathrm{CH})$ \\
\hline 7. & The tasks required in my class (FSE 201) are personally meaningful. (ME) \\
\hline 8. & I like to talk about what I'm doing in my class (FSE 201) with friends or family. (ME) \\
\hline 9. & I feel intimidated by what is required of me in my class (FSE 201). (CO) \\
\hline 10. & My instructor (FSE 201) allows flexibility in the way I perform my tasks. (CH) \\
\hline 11. & I agree with the standards I must meet in my class (FSE 201). (ME) \\
\hline 12. & My success in this class (FSE 201) is under my control. (IM) \\
\hline 13. & I find my class (FSE 201) to be exciting and energizing. (CO) \\
\hline 14. & I have a high level of autonomy in accomplishing my work. $(\mathrm{CH})$ \\
\hline 15. & I find my class (FSE 201) to be interesting. (ME) \\
\hline 16. & I can be creative in the way I perform the tasks required in my class (FSE 201). (CH) \\
\hline 17. & The tasks required by my class (FSE 201) are valuable to me. (ME) \\
\hline & The tasks required by my class (FSE 201) are valued by potential employers. (IM) \\
\hline & $\begin{array}{l}\text { I agree with the meaning my instructor has for what is considered good performance on } \\
\text { ork (FSE 201). (ME) }\end{array}$ \\
\hline & $\begin{array}{l}\text { The following question is a free response question. Would you like to elaborate on any } \\
\text { experiences with the FSE } 201 \text { course this semester? }\end{array}$ \\
\hline
\end{tabular}

$\mathrm{ME}=$ meaningfulness, $\mathrm{CO}=$ competence, $\mathrm{IM}=$ impact, $\mathrm{CH}=$ choice

Table 5: UGTA Experience Empowerment Survey (evaluated against class assigned to assist) 1. I feel confident that I can adequately perform my duties (as a UGTA/SL). (CO) 2. I have the power to make a difference in how things are done in my class (as a UGTA/SL). (IM)

3. My participation (as a UGTA/SL) is important to the success of the class. (IM)

4. My instructor makes me feel inadequate. (CO)

5. I can make an impact on the way things are run in my class. (IM)

6. I look forward to going to my class (as a UGTA/SL). (IM)

7. My instructor believes that he or she must control how I do my work (as a UGTA/SL). $(\mathrm{CH})$

8. Expressing my own attitudes and ideas is rewarded in my class. $(\mathrm{CH})$

9. I possess the necessary skills to perform successfully in class (as a UGTA/SL). (CO) 10. My instructor thinks he or she is always right. $(\mathrm{CH})$

11. I am able to perform the necessary activities to succeed in my class (as a UGTA/SL). $(\mathrm{CO})$ 
12. The following question is a free response question. Would you like to elaborate on any of your experiences as a UGTA/SL during the class which you assisted?

$\mathrm{ME}=$ meaningfulness, $\mathrm{CO}=$ competence, $\mathrm{IM}=$ impact, $\mathrm{CH}=$ choice

The use of the learner empowerment instrument allows us to see how the new design of the program was perceived and correlate that with the reality of implementing the program into the classroom through the UGTA. Analysis of these survey results will answer the third and final question of this study regarding if the new design of the UGTA program provided a high level of empowerment within the UGTA and approval of the addition of task choice.

Historical class data was collected of the total submissions of the self-chosen assignments from records of the gradebook. A total of 416 students were used in the overall analysis of the number of occurrences of self-chosen assignments. While 68 students began the online Qualtrics survey, only 53 students completed the full survey including demographic questions, assignment selection questions, and the empowerment questions. Student responses were grouped and analyzed to determine any statistical significance based on demographic characteristics of interest including first time or returning UGTA/SL, gender, year in school, and assigned role (UGTA/SL). Of the 30 empowerment statements, five of them were written in such a way that a high score of agreement would result describe a negative statement or experience (i.e., "I feel intimidated by what is required of me in my class"). As such the likert scores for those 5 questions were reversed to align such that a strong agreement with a statement would result in a higher student score. A two-sided t-test of uneven variance was used with an alpha criteria of 0.05 to detect statistical significance between the various groups of interest.

\section{Results and Discussion}

In the fall of 2018, 416 students were enrolled as either UGTAs, SLs, or both. The 23 selfchosen assignment options were analyzed to see which assignments were most popularly selected and which assignments were rarely chosen. As seen in Figure 1, the most commonly selected assignments (leading lectures, exam review sessions, and muddiest point surveys) were tasks that had been introduced into the UGTA program for many years and already widely familiar with the supervising faculty. A surprisingly high total is seen on the assignment "Recognizing Your Implicit Bias", which is mostly attributed to the ease of the assignment because it was done on personal time without any interaction from a classroom environment. Another high outlier assignment can be seen in the "4-year plan draft" where a UGTA provides guidance in helping students plan their collegiate career. This was widely popular with SLs since it was a required activity in the first-year engineering course. Students were clearly uninterested in completing two assignments: a guest speaker interview and the hashtag war. These assignments involved a lot of planning outside of class and a motivation to get students involved, which was likely seen as a lot of work steering UGTAs away from these options. Although difficult, we believe they are still valid options to inspire the occasional UGTA looking for a challenge. 


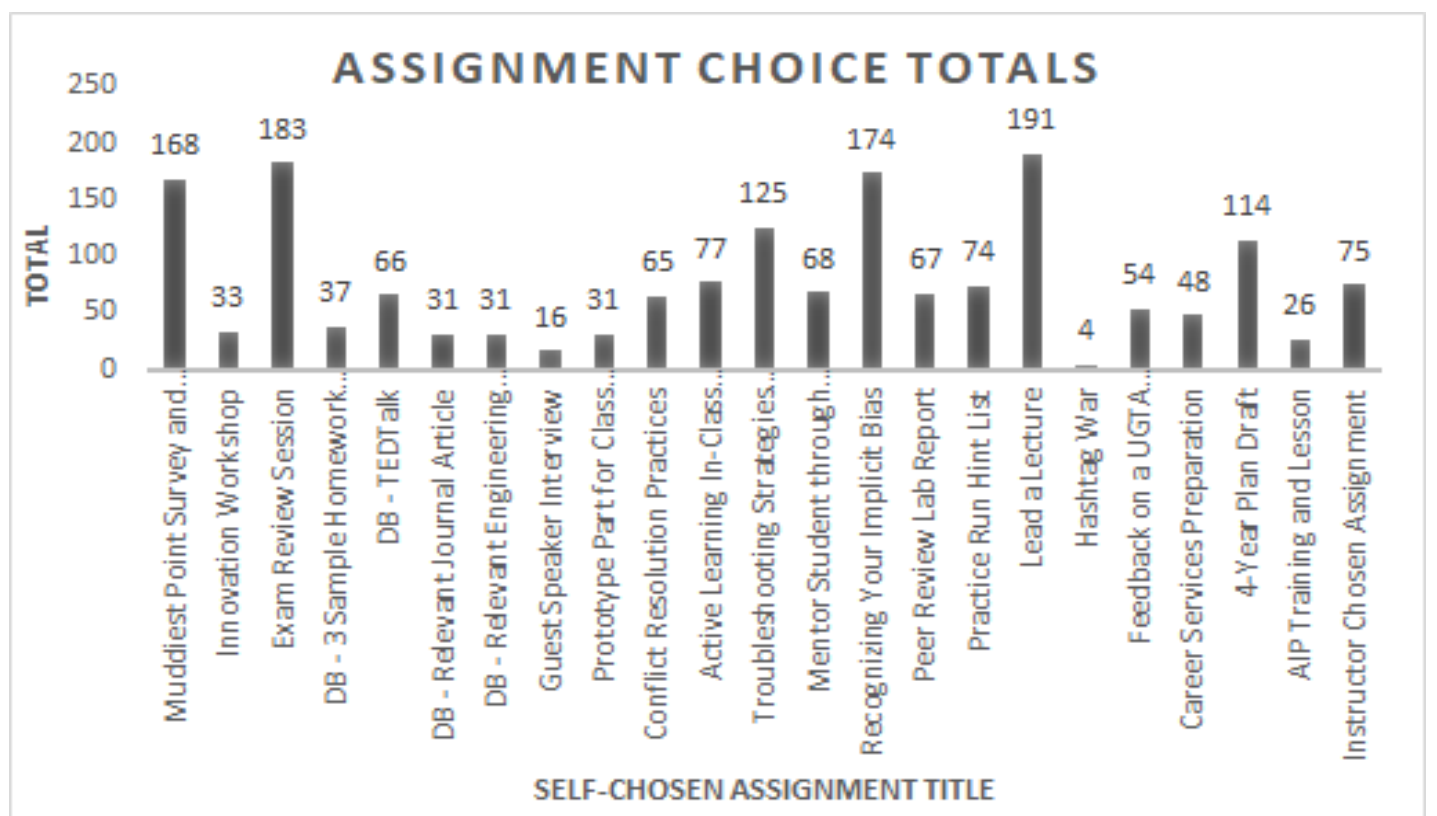

Figure 1: Totals of Self-Chosen Assignments across all UGTA/SL categories

The average likert score across the entire empowerment scale and all responses was 2.95/4. Sixteen of the thirty responses (approximately 53\% percent) had an average score of at least 3 out of 4 . The students surveyed by Phillips [7] had $72 \%$ of the items score as $3 / 4$ in a similar 36statement empowerment instrument focused on learner-focused model. Of the average scores not scoring at least three out of four, 7 were in meaningfulness, 2 were in impact, 3 were in choice, and 2 were in competence. This suggests that the new course format appropriately addresses the revision goals of allowing flexibility to choose their own curriculum and providing distinct skills that allow students to make an impact in their assigned classroom. The low scores in meaningfulness suggest that students have a hard time translating between what was taught in the UGTA course to their role as a UGTA in their assigned course. Student responses echoed this theme, specifying:

and

\section{"I felt like the FSE class and my SL experience were complete separate."}

"I already know the subject that I am assisting my professor with really well. I have taken the class as a student. I know all the little tricks needed to help the students understand the subject better. So I honestly don't see the point of this class."

Figure 2 shows the average scores for the empowerment scale categories of meaningfulness, impact, choice, and competence of both new and returning students. The "both" category indicates that students were new to one role but were returning to the other. Returning UGTAs responding with statistically significant higher scores for the statement "I like to talk about what I'm doing in my class (FSE 201) with friends or family" than first-time UGTAs. However, the first-semester UGTAs indicated statistically significant higher scores for "I find my class (FSE 201) to be exciting and energizing." 


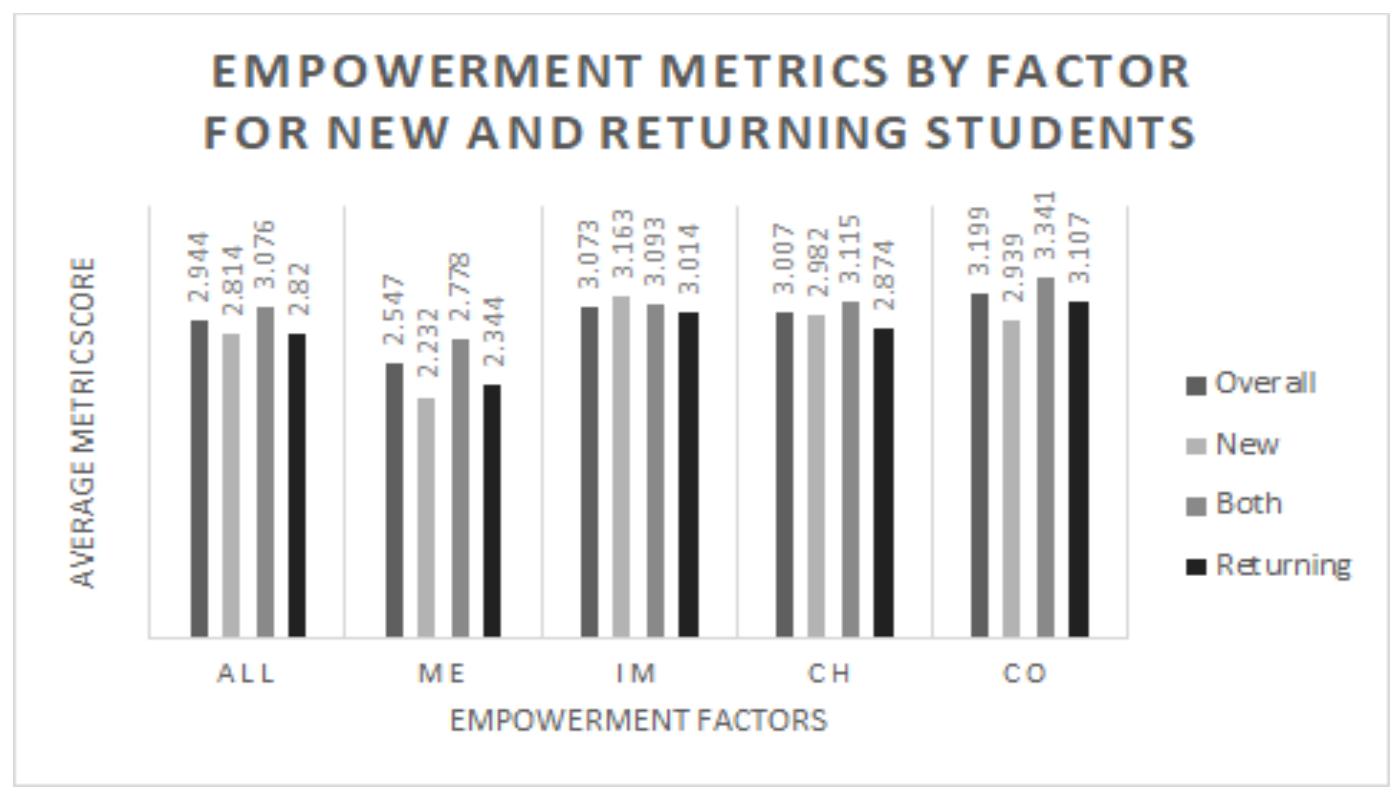

Figure 2: Empowerment Metrics by Factor

When comparing the feedback of first-semester UGTAs compared to returning UGTAs, there was no notable difference between the types of activities students submitted as a part of the selfselecting submissions. One of the goals of this course was to prevent the repetition of assignments for students who had been a UGTA in prior semesters. During the revision of the course, new assignments were added and the goal of the self-selection process was to allow students the flexibility to select assignments best suited for their current course and interests as a UGTA. However, returning students were more likely to have negative views of the course than the first-time students, as indicated by the result of the question "I find my class (FSE 201) to be exciting and energizing," (mean score for returning: 1.55, mean score for new 2.33, $\mathrm{p}=0.028$ ). This tendency was also corroborated by the optional student feedback free-response question about the course in particular. Of the new UGTA students who elected to provide additional comments specific to the first-semester course, two students responded with negative comments, six students with neutral or mixed comments, and six students with positive comments about the FSE201 course. Of the returning students, five responded with negative, three with neutral, and two with positive comments. Feedback from the students showed that further effort should go into planning assignments to keep the experienced UGTAs excited about taking the required complementary coursework and emphasize the link between the coursework to skills gained for their professional development.

Differences with respect to the empowerment instrument was also analyzed by gender. There were no statistically significant differences in the first set of the empowerment questions related to the FSE201 course. However, there were statistically significant differences in responses for some of the phrases relating to the relationship between the UGTA and the course instructor for their UGTA assignment. Male students were more likely to respond negatively to the phrases "My instructor makes me feel inadequate" and "My instructor thinks he or she is always right." This was an interesting finding leading to questioning if faculty are implicitly more sensitive to female UGTAs and harsher to male UGTAs given a society focused on the advancement of 
women in STEM. This will need to be analyzed in further detail before any conclusions can be made.

UGTAs and SLs serve different roles in the classrooms in which they assist. Figure 3 shows the average scores for the students based on their assigned classroom role. SL students had the lowest scores, followed by UGTAs, followed by students who served in both capacities. When comparing their empowerment scores, the SLs indicated they were less likely to agree with the statement "Class (FSE 201) is consistent with my values", "The tasks required by my class (FSE 201) are valued by potential employers", and "I agree with the meaning my instructor has for what is considered good performance on classwork (FSE 201)." These findings suggest future development to add more assignment choices geared towards section leaders and general success courses over technical courses. This also allows the UGTA staff to see that more unity is required when training and interacting with SLs to ensure that they are provided with the same attention and clarity as UGTAs.

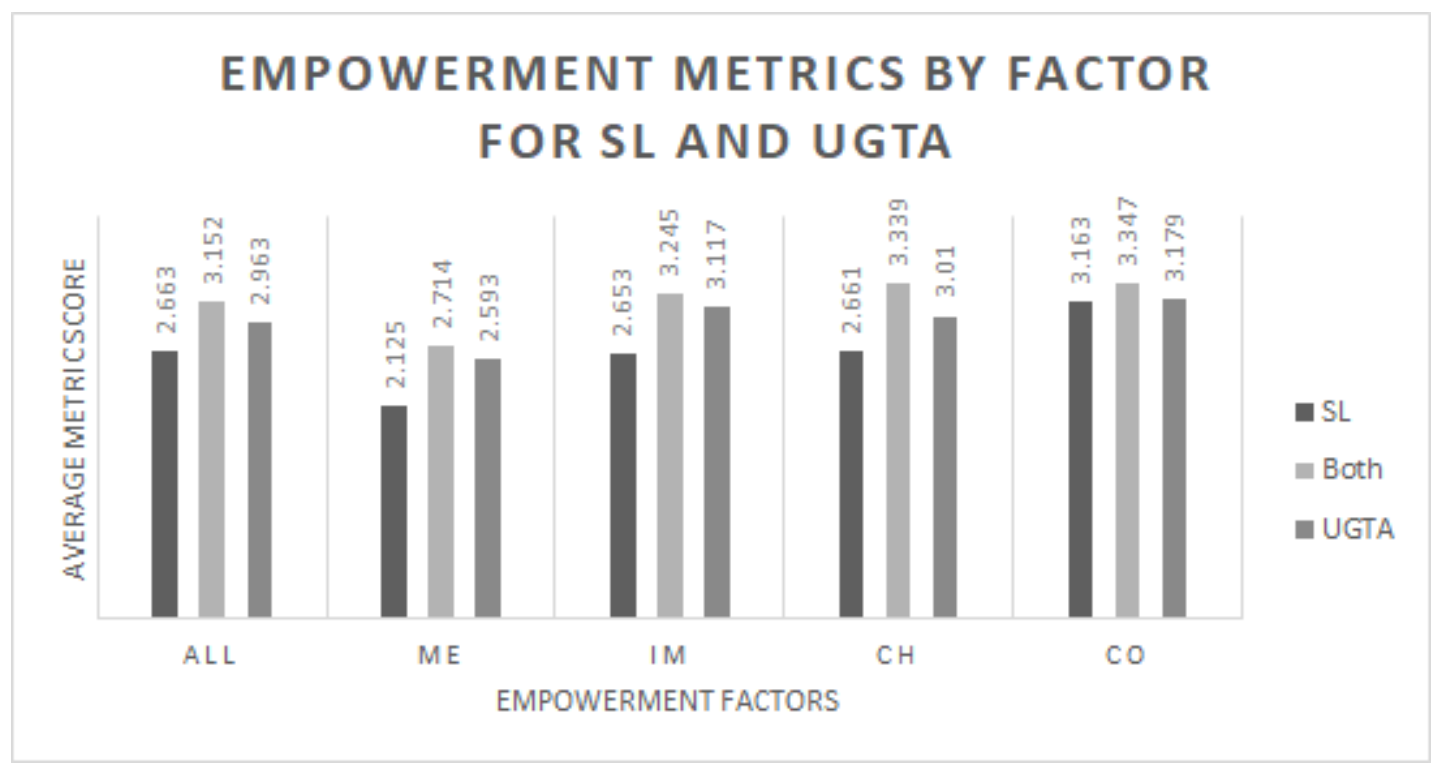

Figure 3: Empowerment Metrics by Assistant Type

No significant correlations or trends were found between the student's year in school (1st, 2nd, 3rd, 4th, or 5+) and their survey responses.

\section{Conclusions and Future Work}

Overall, the updated UGTA program shows promising results in its goals to increase the empowerment in the students hired as undergraduate teaching assistants. Results from the empowerment survey indicate that UGTAs have generally high confidence in their impact, competence, and available choice when assisting students with this program. The addition of choice in tasks based on Thomas' cognitive empowerment model [14], seems to be well received given the empowerment ratings indicating that a generic large-scale program is viable and sustainable by allowing flexibility in leadership and intrinsic choice of tasks. The negative comments regarding the program do not indicate a distaste in the available choices or change overall, but merely in the overall workload indicating that as students repeat employment, there 
is an expectation that jobs should get easier. The structure of this new program allows repeat UGTAs to make each semester different and challenging which is in itself a professional skill hoping to be portrayed (albeit not well communicated) by encouraging lifelong learning and continual increase in performance.

Based on the empowerment factor of meaningfulness as the lowest scored area across all categories of UGTAs, there is significant work that must be developed and added to this program to allow UGTAs to better comprehend that this type of position is a mentoring opportunity for them to learn professional skills and try firsthand a career based in academia. Along with these updates, we feel that a better job must be done communicating with faculty to properly engage their UGTAs into more activities in the classroom so the UGTAs have more chances to feel they are providing meaning and their work has a purpose, all in an effort to increase the empowerment of the valuable UGTAs.

Based on the results of the SL empowerment scales, updates were made in the spring 2019 semester of the program to incorporate more leadership and success assignment choices over technical. These include introducing their class students to research opportunities with professors on campus, highlighting future career opportunities, tutorials on how to properly use libraries, role playing guidance scenarios, small group mentoring, and researching new entrepreneurial teaching innovations. Also in an effort to ensure that SLs are given dedicated support in hopes to improve their empowerment scores, a graduate teaching assistant has been added to the UGTA program staff to hold private meetings with each UGTA or SL throughout the semester to provide one-on-one guidance and support. This is a necessary addition for any program so accountability is well communicated to the student assistants, especially for programs being run at a large-scale such as this.

In the future, this study could be expanded into analyzing which assignments were chosen to complete based on the type of course such as lecture/lab/success/design. This would allow for easier design of UGTA programs for schools with specific needs, instead of generic large-scale populations of assistants. A further study that could take place would be to analyze the empowerment metrics of this study's "new UGTAs" who became "returning UGTAs" to evaluate if the negative comments seen by this study's returning UGTAs was out of frustration of program changes, or if it is a general commonality that returning UGTAs get complacent in their positions and prefer less overarching management. Lastly, since the entrepreneurial mindset core values were used as the inspiration for the program redesign to allow UGTAs to be curious about techniques for connecting with students and creating new value, studies need to be done to evaluate if UGTAs recognize if they gain the skill of entrepreneurially minded thinking in a professional setting. 


\section{References}

[1] Kern Engineering Entrepreneurial Network (KEEN), “The Handbook for EML," KEEN'zine Engineering Unleashed, vol. 5. [Online]. Available:

http://online.fliphtml5.com/zyet/ykie/\#p=1. [Accessed Jan. 28, 2019].

[2] S. J. Krause, J. A. Middleton, E. Judson, K. R. Beeley, and Y. Chen, "Factors Impacting Retention and Success of Undergraduate Engineering Students," in Proceedings of the 122nd ASEE Annual Conference \& Exposition, Seattle, WA, USA, June 14-17, 2015.

[3] J. Crowe, R. Ceresola, and T. Silva, "Enhancing student learning of research methods through the use of undergraduate teaching assistants," Assessment \& Evaluation in Higher Education, vol. 39, no. 6, pp. 759-775, 2014.

[4] M. A McVey, C. R. Bennett, J. H. Kim, and A. Self, "Impact of Undergraduate Teaching Fellows Embedded in Key Undergraduate Engineering Courses," in Proceedings of the 124th ASEE Annual Conference \& Exposition, Columbus, Ohio, USA, June 2017.

[5] L. Wheeler, C. Clark, and C. Grisham, "Transforming a Traditional Laboratory to an InquiryBased Course: Importance of Training TAs when Redesigning a Curriculum," Journal of Chemical Education, vol. 94, iss. 1, pp. 1019-1026, June 2017.

[6] G. Guadagni, H. Ma, and L. Wheeler, "The Benefit of Training Undergraduate Teaching Assistants," in Proceedings of the 125th ASEE Annual Conference \& Exposition, Salt Lake City, UT, USA, June 24-27, 2018.

[7] A. Phillips, K. M. Kecskemety, and D. A. Delaine, "First-year Engineering Teaching Assistant Training: Examining Different Training Models and Teaching Assistant Empowerment," in Proceedings of the 125th ASEE Annual Conference \& Exposition, Salt Lake City, UT, USA, June 24-27, 2018.

[8] E. Gehringer, "Working Effectively With Teaching Assistants," in Proceedings of the 2009 ASEE Annual Conference \& Exposition, Austin, TX, USA, June, 2009.

[9] M. Mendenhall and W. Burr, "Enlarging the role of the undergraduate teaching assistant," Teaching of Psychology, vol. 10, no. 3, pp. 184-185, Oct 1983.

[10] L. Prieto and L. R. August, "Guiding the UTA experience: The modified integrated developmental model," in American Psychological Association convention, San Diego, CA, USA, 2010.

[11] D. Shannon, D. Twale, and M. Moore, 'TA teaching effectiveness: The Impact of Training and Teaching Experience," The Journal of Higher Education, vol. 69, no. 4, pp. 440-466, July 1998. 
[12] D. Christenson, D. Baldwin, M. Brundrett, P. Monaco, K. Nguyen, and A. Morse, "Student and Teaching Assistant Perspectives on Characteristics of an Effective Teaching Assistant" in Proceedings of the 122nd ASEE Annual Conference \& Exposition, Seattle, WA, USA, June 14-17, 2015.

[13] J. Weidert, A. Wendorf, R. Gurung, and T. Filz, "A Survey of Graduate and Undergraduate Teaching Assistants,” College Teaching, vol. 60, no. 3, pp. 95-103, July 2012.

[14] K. Thomas and B. Velthouse, "Cognitive Elements of Empowerment: An "Interpretive" Model of Intrinsic Task Motivation," The Academy of Management Review, vol. 15, no.4, pp. 666-681, Oct. 1990.

[15] J. Owen, "Peer educators in classroom settings: Effective academic partners" in Emerging issues and practices in peer education, New directions for student services, vol. 133, L. B. Williams, Ed. San Francisco: Jossey-Bass, 2011, pp. 55-64.

[16] C. Robinson, and J. Collofello,(2012, June), 'Utilizing Undergraduate Teaching Assistants in Active Learning Environments," in Proceedings of the ASEE Annual Conference \& Exposition, San Antonio, TX, USA, June 2012.

[17] A. Frymeir, G. Shulman, and M. Houser, "The development of a learner empowerment measure," Communication Education, vol. 45, no. 3, pp. 181-199, 1996. 